\title{
The Role of Empathy in Justice Sensitivity
}

Isabella Polito

Irvine Valley College (CA)

Suggested bibliographic reference

Polito, I. (2021). The role of empathy in justice sensitivity. Psi Beta Journal of Research, 1(1), 1-7. https://doi.org/10.54581/IAVB5683

\begin{abstract}
What role does empathy play in moral decision-making? The present study examined the relationship between several empathy measures and empathy's role in a person's justice sensitivity. Prior research shows that empathy is a construct having several components. Research also suggests that an individual's empathy can influence their thinking when serving social justice. In this study, I asked participants to complete several scales designed to measure empathy and justice sensitivity. Next, participants judged a defendant's guilt. Participants read a description of Juan Rodriguez's case, a man currently facing twenty years in jail for accidentally leaving his twins in his car, resulting in their deaths. Participants' scores on several empathy scales were compared to their judgment of the defendant's guilt. I hypothesized that subscales of empathy would be positively related to several perspectives of justice sensitivity. Next, I hypothesized that as participant empathy for the defendant, rather than the victims, increased, participants would favor less severe charges. One hundred and twenty-two (39 males, 83 females) participants enrolled in psychology courses at a southern California community college volunteered to complete a 20-minute questionnaire for course credit. A majority of the hypotheses were supported. Results found significant correlations among components of empathy and between the per-spectives of justice sensitivity. Participants' differential empathy for the father and the twins influenced the severity of the punishment they chose for the defendant. The results suggest that empathy can im-pact specific sensitivities of justice and perceptions in real-life situations. Further research is needed to understand further how empathy affects moral decision-making.
\end{abstract}

Keywords: empathy, perspective-taking, empathic concern, justice

People have an innate desire to connect socially with others. Empathy, the ability to see things from another person's perspective, can foster social connectivity. But empathy has both positive and negative aspects. While it can bring feelings of joy and happiness in good circumstances, in times of despair, empathy can bring sadness and distress while attempting to comfort others experiencing difficult times. Empathy, therefore, can be unpleasant at times, hindering its everyday use. The consequence is the loss of empathy's potential for bringing people together.
Historically, researchers have regarded empathy as a component of Emotional Intelligence, but recent research has studied empathy as an independent psychological construct. Some have described empathy as having two subcategories, Perspective-taking and Empathic Concern (Cameron et al., 2019; Longmire \& Harrison, 2018; Murphy \& Lilienfeld, 2019; Oliver et al., 2018; Pekaar et al., 2019; Van Der Graaff et al., 2014; Decety \&Yoder, 2016). Both dimensions are crucial in determining an individual's ability to empathize but differ in how they impact an individual's perspective in situations. Perspective-taking, 
described as cognitive empathy or self-focused empathy, is a form of empathy that focuses primarily on interpreting other individuals' emotions and circumstances while not invoking one's own emotions. Alternatively, Empathic Concern, sometimes named "other-focused" or "affective empathy," involves the ability to share and understand another person's emotional experience objectively.

Investigators have found that empathy includes multiple components. They have studied its lifespan development and the ways empathy manifests in different settings, including the workplace. One study on empathy's evolution (Van Der Graff et al., 2014) found significant gender differences and evidence that empathy is an integral part of moral development. Studies of the workplace setting found that other-focused emotional intelligence, like perspective-taking, helped decrease subjective stress, while empathic concern or self-focused emotional intelligence benefits task performance (Pekaar, et al., 2019). Supporting these findings, Longmire \& Harrison (2018) found that empathic concern is more motivating than perspective-taking in the workplace. However, perspective-taking is more beneficial for supervisors' relationships with their employees. Cameron et al. (2019) found that research participants often suppress empathy due to its cognitive costs when assessing the costs and benefits of choosing an empathetic route when dealing with a situation. That study suggested that individuals would rather avoid empathy, even if it were the correct response to the circumstance, because of its cognitive and emotional consequences.

Researchers have conducted empathy-related research in social justice involving motivation for justice and prejudice development within the courtroom. Studies on empathy's involvement in bias suggest that to combat anti-immigrant attitudes among adolescents, there should be a specific focus on perspective-taking and empathic concern (Miklikowska, 2018). A study on social empathy among social work students examined the relationship between empathic concern, perspective-taking, political affiliations, and stances on social justice policies. That study concluded that social empathy helped promote understanding and advanced social justice (Segal \& Wagaman, 2017). Some research has investigated empathy's place in the court system concerning justice sensitivity. Researchers describe justice sensitivity as an individual's desire and motivation to support certain principles of justice (Decety \& Yoder, 2016). Decety and Yoker (2016), in their study, defined cognitive empathy, affective empathy, and motivational empathy. They found that emotional empathy was not associated with justice sensitivity. Instead, they found that cognitive empathy (or perspective-taking) and empathic concern were correlated to individuals' justice sensitivity, while emotional empathy was not. Another study investigated whether empathy-induced altruism, defined as a selfless concern for others' well-being, could lead to violations of moral justice principles (Batson et al., 1995). That study found that individuals encouraged not to empathize were more likely to uphold social justice morals. A similar study investigated the effects of empathy manipulation on jurors' decisions in the courtroom. The findings indicated that the participants encouraged to take the defendant's perspective found them less guilty of the crime than participants who were not. Through perspectivetaking, participants also rated the child abuse as a significant mitigating factor in the killing of the parents by their children (Haegerich \& Bottoms, 2000). These findings provide insight into empathy in terms of individual justice sensitivity and provide the impetus for further justice system research.

Nonetheless, the role of empathy in the court system remains controversial but suggests it can have a beneficial influence. The United States court of law is one of few in the world that grants people the constitutional right to have a jury of their peers throughout their trial (United States Constitution: Amendment IX, 1793). Defendants 
can enjoy a jury of their peers or "equals," and jury composition can range widely by ethnicity, race, gender, and sexual orientation. Jurors, of course, hear evidence and decide on the defendant's guilt or innocence. Our jury system is a form of checks and balances and a way to closely examine the defendant's alleged crime's perspective and reasoning. In other words, a jury of peers is the empathy factor in a court of law.

The present study had two parts. Part I explored the relationships among several well-regarded empathy-related measures. Part II was a case study in which participants read a scenario and responded by choosing the severity of a courtroom defendant's prison sentence. For Part I of the study, reflecting on prior research in this area, I hypothesized a positive relationship between General Empathy and Empathic Concern. Similarly, I hypothesized a positive relationship between Personal Distress and Empathic Concern. I expected to find other relationships among the measures when exploring the resulting data set. For Part II, that involved an actual-life case study, I hypothesized that individuals who empathized with the defendant would arrive at a less harsh sentence. In contrast, those who had greater empathy for the defendant's victims would choose a harsher punishment.

\section{Method}

This study used a correlational design. After receiving the Institutional Review Board's approval to move forward, the researcher visited various psychology classrooms to recruit participants for the online study. Young adults (39 females, 83 males, Mage $=21.52$, age range: 18 59) from various community college classes agreed to complete the research questionnaire. Professors agreed to compensate the participants with a small amount of extra credit. The participants $(n=122)$ received instructions to create an account through a third-party program, the Sona System, then register to take the questionnaire and receive credit for their participation. The researcher removed five participants' data because they were underage. It was necessary to remove another eight participants' data following edits to the case study description.

The scales used in the study included the Interpersonal Reactivity Inventory and the Justice Sensitivity Scale. The Interpersonal Reactivity Inventory (IRI) consists of twenty-eight items that focus on the components of empathy defined as Perspective-taking, Fantasy, Empathic Concern, and Personal Distress (Davis, 1980). For this study's purpose, the Fantasy items were summed to form a composite score but were not individually analyzed. I also administered the Justice Sensitivity Scale to determine participants' motivation for justice. The Justice Sensitivity Scale consists of forty items, divided into four ten-item sections that focus on four perspectives: Victim Sensitivity, Observer Sensitivity, Beneficiary Sensitivity, and Perpetrator Sensitivity (Schmitt et al., 2010). Also, a real-life case description about a man, Juan Rodriguez, was presented to the participants. Participants read and responded to questions regarding empathy and what they deemed to be the most appropriate sentence for the crime (see the Appendix).

\section{Results}

Descriptive statistics were computed for each of the empathy measures (see Table 1 for a summary), Next, relationships among the measures of empathy were computed. The results supported the first hypothesis. More specifically, there was a strong positive relationship between Empathic Concern and General Empathy, $r(120)=.29, p<$ .01. Secondly, there was a positive relationship between Personal Distress and Empathic Concern. Specifically, $r(120)=.22, p<.01$. Further exploration found a negative relationship rather than a positive relationship between Personal Distress and Perspective-Taking, $r(120)=-.18, p<.01$.

Lastly, the case study hypothesis was that the punishment severity would differ for participants who empathized with the victims (the twins in the case study) and those who empathized with the accused (the father), $x 2(8)=15.81, p<.05 ; \phi$ 
$=.37$. As shown in Table 2, the severity of the charge chosen by participants increased if they empathized with the twins and decreased when they empathized with the father. While most par- ticipants chose a 5-year prison term, those having greater empathy for the twins were more likely to recommend even greater punishment (e.g., incarceration for 15 or more years) for the accused.

Table 1

Measures Means and Standard Deviations

\begin{tabular}{ccc}
\hline Measures & Mean & Standard Deviation \\
\hline General Empathy & 3.21 & .30 \\
Empathic Concern & 3.88 & .67 \\
Perspective-taking & 3.83 & .59 \\
Personal Distress & 2.76 & .66 \\
General Justice Sensitivity & 3.36 & .62 \\
Victim Sensitivity & 3.10 & .78 \\
Observer Sensitivity & 3.40 & .78 \\
Beneficiary Sensitivity & 3.18 & .78 \\
Perpetrator Sensitivity & 3.76 & .81 \\
\hline
\end{tabular}

Note. The Interpersonal Reactivity Index is from Davis (1980). The index includes the subscales of Empathic Concern, Perspective-taking, Personal Distress, and its composite score provided the General Empathy score. The Justice Sensitivity Inventory is from Schmitt et al. (2010). The inventory included the subscales of Victim Sensitivity, Observer Sensitivity, Beneficiary Sensitivity, Perpetrator Sensitivity, and its composite score provided the General Justice Sensitivity score.

Table 2

Charges Chosen by Participants

\begin{tabular}{lccccc}
\hline $\begin{array}{c}\text { Who participants em- } \\
\text { pathized with more }\end{array}$ & $\begin{array}{c}\text { No } \\
\text { Charge }\end{array}$ & $\begin{array}{c}\text { Endangerment of } \\
\text { a child } \\
(1 \text { year })\end{array}$ & $\begin{array}{c}\text { Criminal Neg- } \\
\text { ligence } \\
(5 \text { years })\end{array}$ & $\begin{array}{c}\text { Two accounts of Man- } \\
\text { slaughter (15 years) }\end{array}$ & $\begin{array}{c}\text { A more signifi- } \\
\text { cant charge }\end{array}$ \\
\hline The father & $21.62 \%$ & $27.03 \%$ & $43.24 \%$ & $2.70 \%$ & $5.41 \%$ \\
\hline The twins & $4.68 \%$ & $15.63 \%$ & $50 \%$ & $21.88 \%$ & $7.81 \%$ \\
\hline Neither & $15.38 \%$ & $15.38 \%$ & $46.15 \%$ & $7.69 \%$ & $15.38 \%$ \\
\hline
\end{tabular}

Note. The percentages represent the number of individuals within the groups that empathized with the father, the twins, or neither, and the charge they believed would be appropriate for Mr. Rodriguez.

\section{Discussion}

The results supported the study's three hypotheses. There was a strong positive relationship between Empathic Concern and General Empathy, and there was a positive relationship between Personal Distress and Empathic Concern. Finally, the severity of the charge chosen by participants in- 
creased if they empathized with the twins and decreased when they empathized with the father.

These findings supported prior research findings, specifically, the relationships found among General Empathy, Empathic Concern, and Perspective Distress. Oswald (1996), for example, compared the impact of empathic concern and perspective-taking on altruistic helping; she found that individuals who focused on affective empathy instead of cognitive empathy were much more likely to help an individual. Oswald's study helps to explain the present results. Both empathic concern and perspective-taking are essential, but empathic concern carries more influence in general empathy, explaining a stronger relationship between empathic concern and general empathy than the relationship between general empathy and perspective-taking. A prior study found that most adults, when provided with options on how to respond to a scenario, deliberately avoided using empathy, even when it was considered the correct choice, due to its cognitive and emotional costs (Cameron et al., 2019). As a result of that study's findings of the relationships between empathy components, I expected that personal distress would correlate positively with general empathy and its elements of empathic concern and perspective-taking. The results found a positive relationship between personal distress, general empathy, and empathic concern as expected, but not perspective-taking. It appears that personal distress plays a key role in empathy, as it can be the deciding factor on whether or not individuals choose to experience it. The negative relationship between personal distress and perspective-taking may be due to the cognitive component of empathy, possibly inhibiting individuals' emotional distress.

This study's findings are comparable to a study investigating social work students' empathy to various other factors, including political affiliation and stances on certain policies. That study found that teaching social empathy helped students understand and advance in economic and social justice (Segal \& Wagaman, 2017). The cur- rent study's results found a positive relationship between general empathy and general justice sensitivity, as would be expected. Also, there was a positive relationship between general empathy and all perspectives of justice sensitivity. Finally, the finding that participants chose punishment levels according to whom they felt greater empathy (the father or the twins) supported prior research. An earlier study also investigated the effects of empathy manipulation on jurors' decisions in the courtroom. In that study, participants read trial transcripts involving the killing of a parent by a child in self-defense due to an environment of ongoing abuse. The findings indicated that participants encouraged to take the defendant's perspective found defendants less guilty of the crime (Haegerich \& Bottoms, 2000). These findings parallel the current study's results; those who empathized with the father leaned toward a lesser charge than those who empathized more with the twins.

This study's findings provide food for thought in light of a defendant's right within the American court system to a jury of their peers. These findings suggest empathy can play in jurors' justice sensitivities and their motivation and thought processes when making decisions as jury members. The literature review did not find a consensus on whether or not circumstances and environmental factors should be considered when judging a crime. If they are, to what extent? Various factors clearly can change the perspectives and methods of reasoning when understanding and assigning blame for a crime. Should the jury selection process include juror empathy? However, as shown in this study, individual empathy is complex and has multiple factors and components, which are undoubtedly too challenging to isolate during jury selection. The findings may initiate a conversation within the legal community about the possible weaknesses of the current jury selection process and the implications that juror empathy profiles can have on decisions ranging from small fines to years or even life sentences, as 
in Juan Rodriguez's case. Research should continue to explore this area. Further research may play a significant role in furthering our understanding of empathy's role in justice sensitivity and how it impacts the American court system.

This study was completed within a short period, resulting in several limitations. The study would benefit from a replication having a larger number and range of participants. Future research could benefit from gathering additional information on participants' past experiences and knowledge of situations depicted in the case study. Finally, this study used a correlational design. An experimental design that manipulates various empathy components might further our understanding of how people respond to real-life situations, such as the Juan Rodriguez situation.

\section{References}

Batson, C. D., Klein, T. R., Highberger, L., \& Shaw, L. L. (1995). Immorality from empathy-induced altruism: When compassion and justice conflict. Journal of Personality and Social Psychology, 68(6), 1042-1054. https://doi.org/10.1037/0022$\underline{3514.68 .6 .1042}$

Cameron, C. D., Hutcherson, C. A., Ferguson, A. M., Scheffer, J. A., Hadjiandreou, E., \& Inzlicht, M. (2019). Empathy is hard work: People choose to avoid empathy because of its cognitive costs. Journal of Experimental Psychology: General, 148(6), 962-976. https://doiorg.ezproxy.ivc.edu/10.1037/xge0000595.supp (Supplemental)

Davis, M. H. (1980). A multidimensional approach to individual differences in empathy. JSAS Catalog of Selected Documents in Psychology, 10, 85.

Decety, J., \& Yoder, K. J. (2016). Empathy and motivation for justice: Cognitive empathy and concern, but not emotional empathy, predict sensitivity to injustice for others. Social Neuroscience, 11(1), 1-14. https://doiorg.ezproxy.ivc.edu/10.1080/17470919.2015.102 $\underline{9593}$

Delay in grand jury action in death of twins left in car. A.P. Regional State Report - New York. Associated Press DBA Press Association. Retrieved from https://search-ebscohost-

com.ezproxy.ivc.edu/login.aspx?direct=true $\& \mathrm{db}=$ nsm\&AN=AP513405088b3b4dc1a2da75383e 783 $850 \&$ site $=$ ehost-live \&scope $=$ site

Haegerich, T. M., \& Bottoms, B. L. (2000). Empathy and jurors' decisions in patricide trials involving child sexual assault allegations. Law and Human Behavior, 24(4), 421-448. https://doi.org/10.1023/A:1005592213294

Longmire, N. H., \& Harrison, D. A. (2018). Seeing their side versus feeling their pain: Differential consequences of perspective-taking and empathy at work. Journal of Applied Psychology, 103(8), 894-915. https://doiorg.ezproxy.ivc.edu/10.1037/ap10000307.supp (Supplemental)

Miklikowska, M. (2018). Empathy trumps prejudice: The longitudinal relation between empathy and anti-immigrant attitudes in adolescence. Developmental Psychology, 54(4), 703-717. https://doiorg.ezproxy.ivc.edu/10.1037/dev0000474

Murphy, B. A., \& Lilienfeld, S. O. (2019). Are selfreport cognitive empathy ratings valid proxies for cognitive empathy ability? Negligible metaanalytic relations with behavioral task performance. Psychological Assessment, 31(8), 1062 1072. https://doi.org/10.1037/pas0000732

Oliver, L. D., Vieira, J. B., Neufeld, R. W. J., Dziobek, I., \& Mitchell, D. G. V. (2018). Greater involvement of action simulation mechanisms in emotional vs cognitive empathy. Social Cognitive \& Affective Neuroscience, 13(4), 367-380.

https://doiorg.ezproxy.ivc.edu/10.1093/scan/nsy013

Oswald, P. A. (1996). The effects of cognitive and affective perspective-taking on empathic concern and altruistic helping. Journal of Social Psychology, 136(5), 613-623. https://doiorg.ezproxy.ivc.edu/10.1080/00224545.1996.971 $\underline{4045}$

Pekaar, K. A., Bakker, A. B., Born, M. P., \& van der Linden, D. (2019). The consequences of self-and other-focused emotional intelligence: Not all sunshine and roses. Journal of Occupational Health Psychology, 24(4), 450-466. https://doi.org/10.1037/ocp0000134

Schmitt, M., Baumert, A., Gollwitzer, M., \& Maes, J. (2010). The Justice Sensitivity Inventory: Factorial validity, location in the personality facet 
space, demographic pattern, and normative data.

Social Justice Research. 23(2-3), 211-238.

10.1007/s11211-010-0115-2.

Segal, E. A., \& Wagaman, M. A. (2017). Social empathy as a framework for teaching social justice. Journal of Social Work Education, 53(2), 201

211. https://doi-

org.ezproxy.ivc.edu/10.1080/10437797.2016.126

$\underline{6980}$

United States Constitution Amendment XI (1794)

Van der Graaff, J., Branje, S., De Wied, M., Hawk, S., Van Lier, P., \& Meeus, W. (2014). Perspectivetaking and empathic concern in adolescence: Gender differences in developmental changes. Developmental Psychology, 50(3), 881-888. https://doi-org.ezproxy.ivc.edu/10.1037/a0034325

\section{Appendix}

\section{Case Description}

Participants read and responded to questions regarding the following real-life scenario.

Juan Rodriguez is a 39-year-old married man. He is an Iraq War veteran with three children. Mr. Rodriguez normally takes his 1-year-old twin daughters to daycare in the morning before going to his 8-hour shift at the James J. Peters VA Medical Center in Bronx, New York. One day, there was construction on his usual path, so he took an alternate route. After his shift was over, he returned to his car and discovered the bodies of his 1-year-old twin daughters strapped to their car seats in temperatures reaching the high 80 's. Rodriguez told police officers that he believed he had dropped them off at school before arriving to work that morning. Rodriguez, distraught, told officers, "I blanked out, my babies are dead, I killed my babies." Rodriguez's defense attorneys told reporters that Rodriguez was beside himself and did not intend to kill his babies ("Delay in grand jury action," 2019) 